\title{
Primeiro registro de Exserohilum rostratum (anamorfo de Setosphaeria rostrata) causando manchas foliares em açaizeiro no B rasil
}

\author{
Luiz Sebastião Poltronieri ${ }^{1}$, J aqueline R osemeire Verzignassi ${ }^{2}$, Ruth L inda Benchimol ${ }^{1}$ e Francisco Chagas Oliveira F reire ${ }^{3}$
}

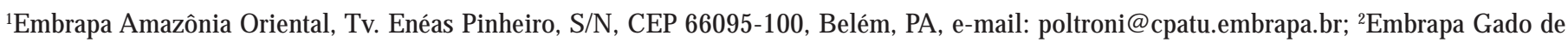
Corte, Campo Grande, M S; ${ }^{3}$ Embrapa A groindústria Tropical, Fortaleza, CE.

A utor para correspondência: Luiz S. Poltronieri

Data de chegada: 10/05/2007. A ceito para publicação em: 06/12/2007

0 açaizeiro (Euterpe oleracea $M$ art.) é uma palmeira que ocorre em várias regiões da A mazônia. A procura pela polpa dos frutos da palmeira para a fabricação de sucos e sorvetes vem sendo al avancada em função do seu potencial energético, cientificamente comprovado. Estas características, já conhecidas pela população local, também vêm ganhando espaço nos grandes centros nacionais, causando aumento significativo na procura pelo produto. As utilidades da planta vão desde o tradicional "vinho do açaí", até cremes, sucos, sorvetes, picolés, licores, mingau, entre outros. 0 caroço pode ser utilizado como adubo orgânico e, quando queimado, produz fumaça repelente de insetos. A produção anual de frutos é de 160 mil tonel adas no Pará, mas é esperado aumento na produção quando as áreas de cultivo apresentarem níveis satisfatórios de manejo, estimando-se a produtividade em 8 t/ha. 0 valor anual da produção de frutos de açaizeiro no Pará é de, aproximadamente, 66 milhões de reais.

Durante visita realizada em áreas de cultivo de açaizeiro no M unicípio de São Domingos ( $M$ A), observaram-se plantas com seis meses de idade apresentando pequenas manchas foliares de coloração pardo-avermelhadas que coalesciam, resultando no secamento das folhas (Fig. 1).

De amostras de folhas infectadas procedeu-se 0 isolamento em meio BDA. A pós cinco dias, colônias fúngicas foram obtidas e os isolados enviados ao Dr. Paul Kirk (Micologista do CABI BIOSCIEN CE, E gham, Inglaterra) para a identificação. 0 fungo foi identificado como sendo Setosphaeria rostrata K. J. Leonard, anamorfo Exserohilum rostratum (D rechsler) L eonard \& Suggs. Setosphaeria rostrata apresenta, na sua fase anamórfica, conidióforos com até 200 $\mu \mathrm{m}$ de comprimento, solitários ou em pequenos grupos, de coloração marrom ou oliváceos. Os conídios, com comprimento de 40 a $180 \mu \mathrm{m}$ elargura de 14 a $22 \mu \mathrm{m}$, são retos ou ligei ramente curvos, afinando nas extremidades, com uma das extremidades formando um bico pronunciado, com seis a 16 septos, de coloração café dourado mais pronunciada no centro e hilo protuberante. 0 s isolados estão sendo preservados na micoteca do L aboratório de F itopatologia da E mbrapa A mazônia Oriental.

Testes de patogenicidade foram real izados em mudas de açaizeiro,

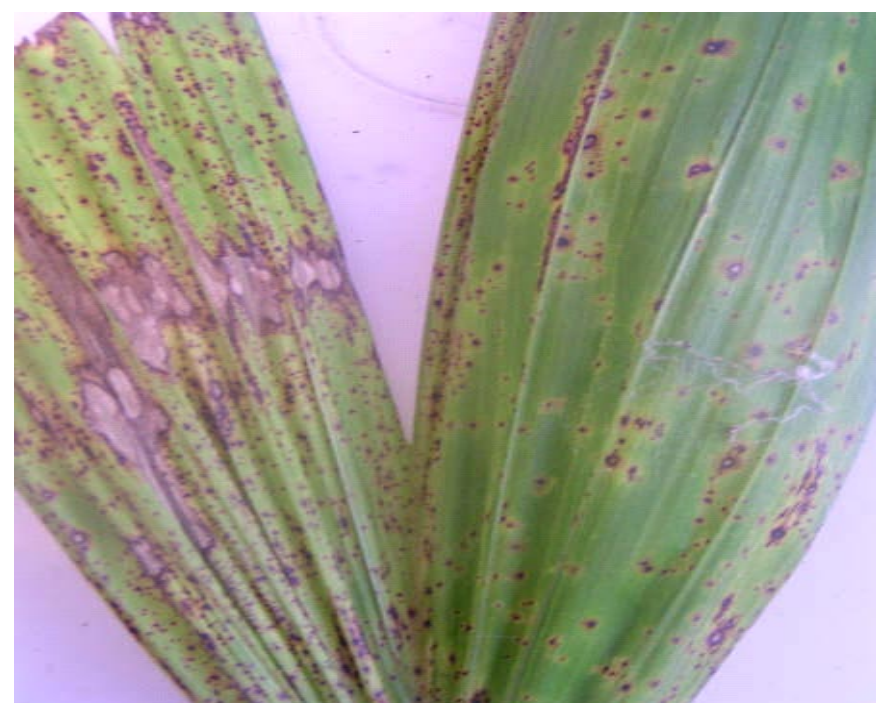

Figura 1. Folha de açaizeiro apresentando manchas foliares causadas por Exserohilum rostratum (anamorfo de Setosphaeria rostrata).

com três meses de idade, e de coqueiro, com 12 meses de idade. Para tanto, procedeu-se ferimento (com agul has) das folhas e pulverização com suspensão de conídios ( 4 x $10^{5}$ conídios $/ \mathrm{mL}$ ). A pós a inoculação, as plantas foram mantidas em câmara úmida por três dias e, dez dias após, os sintomas da doença foram reproduzidos em ambos os hospedeiros. 0 reisolamento foi efetuado, comprovando-se a patogenicidade do isolado.

O fungo apresenta como principais hospedeiros Triticum aestivum e plantas dos gêneros Arachis, Bambusa, Cocus, Chloris, Capsicum, Curcuma, Cynodon, Digitaria, Hibiscus, Lens, Lycopersicon, Mormodica, Oryza, Pennisetum, Vigna, Psidium, Eucaplyptus, Saccharum, Solanum, Sorghum, Triticum, Mangifera, Beta, Coryandrum, Cucuminum, Linum, Phaseolus, Sesamum, Zea, além de várias plantas da família Poaceae. Este é o primeiro registro da fase anamórfica de Setosphaeria rostrata em açaizeiro no B rasil. 